\title{
Infrastructure Connectivity and Enterprise Performance: Quasi-natural Experiment based on China Railway Express
}

\author{
Ruifei Jia \\ School of Business, China University of Political Science and Law, Beijing, China \\ 772784366@qq.com
}

\begin{abstract}
The Belt and Road initiatives (BRI) has promoted the trade exchanges between China and the countries along the route. The opening of the CHINA RAILWAY Express (CR express), its core achievement, has promoted the infrastructure connection between China and other countries, and has a profound impact on the development of Chinese enterprises. Under the profound adjustment of the current international investment and trade pattern and the rules of multilateral investment and trade, it is of great practical significance and theoretical value to study the impact of the opening of CR express on enterprise performance. Based on the micro data of 8,770 A-share manufacturing listed companies from 2009 to 2015, this paper constructs Differences-in-Differences model (DID) to investigate the impact of the launch of CR express on enterprise performance. The study found that the opening of CR expresses significantly improved enterprises performance. Moreover, with the increase of the distance between the spokes, the promoting effect is gradually weakened. This paper reveals the promotion and influencing mechanism of the opening of CR express on enterprise performance, which has some enlightening effect on the further research of CR express station planning and other issues.
\end{abstract}

Keywords: Infrastructure; Enterprise Performance; CR Express; DID.

\section{Introduction}

Enterprise performance is a barometer of a company's operating conditions, a tool to reflect the profitability, asset operation level, debt paying ability and subsequent development ability of the enterprise, and an important factor for shareholders and investors and so on. Enterprise performance is also affected by internal and external environment. On the one hand, internal factors such as enterprise's own debt and innovation degree will have an impact on enterprise performance; On the other hand, industry, region, transportation and other external factors will also have a significant impact on enterprise performance.

Infrastructure can promote labor input and capital transportation, and promote productivity improvement through the dissemination and exchange of advanced technology and management experience (Fang Fuqian et al., 2020). The core content of BRI is to promote infrastructure construction and connectivity, connect national policies and development strategies of various countries, so as to deepen practical cooperation, promote coordinated and interconnected development, and achieve common prosperity. The opening of CR express is one of the important achievements. Since the launch of Chongqing new European railway in 2011, the total number of cities in China has increased to 30, reaching 106 cities in 21 European countries. In 2020, despite the impact of the COVID-19 epidemic on the global economy, due to the advantage of international railway connectivity, the CR express is still developing rapidly, breaking the " 10,000 trains" mark for the first time, with a total of 12,406 trains opened in the whole year, a year-on-year increase of $50 \%$. The opening of the CR express has strengthened the trade between China and the countries along the Belt and Road, and promoted the development of enterprises. the CR express has been widely concerned by scholars since its opening, and the research of CR express has important practical significance and theoretical value.

Literature has discussed the economic effect of infrastructure construction level on enterprise development. Transportation infrastructure has a significant impact on the export of enterprises (Wang Yongjin and Huang Qing, 2017). In recent years, scholars have studied the impact of highways or high-speed rail on the development of urban enterprises, such as high-speed rail on enterprise 
productivity (Shi Zhenkai et al., 2018), enterprise evolution (Zhang Tianhua et al., 2018) and enterprise inventory (lihan and Tang Limiao, 2015), in addition, there are a few scholars have studied the impact of high-speed rail on enterprise performance (Ma Tao et al., 2020).Under the BRI, the CR express is the representative of international connectivity. So, can the CR express promote corporate performance? Therefore, this paper studies the impact of infrastructure connectivity on enterprise performance based on the Quasi-natural experiment of the opening of CR express.

The contribution of this paper is mainly reflected in the following two aspects: (1) It enriches the research on the influencing factors of enterprise performance. Studies have proved the impact of the opening of high-speed rail on enterprise performance. But they pay more attention to the study of domestic transportation connectivity, ignoring the transportation infrastructure connectivity between China and other countries. Therefore, this paper uses the core achievement of Belt and Road -- the opening of CR expresses to carry out DID analysis and provide some new evidence for the promotion of transportation infrastructure connectivity to enterprise performance. (2) The direct promotion effect and influence mechanism of CR express on enterprise performance are identified and tested by means of DID estimation. This not only provides new micro evidence for the effectiveness of CR express, to encourage Chinese enterprises to actively expand the international market, but also provides certain evidence for the government to conduct further research on the station planning and other issues under BRI, and provides reference for the BRI follow-up research.

\section{Literature Review}

According to the existing literature, the research results related to this paper mainly involve the following three aspects:

First, the research on the influencing factors of enterprise performance. Many scholars have discussed it from different perspectives. Chen Deping and Zeng Zhihai (2012) established the model of capital structure and enterprise performance by GMM method, and the structure showed that capital structure has a significant impact on enterprise performance. Based on the sample data of 251 enterprises, Li Jianli (2009) included redundant resources in the impact of exploratory innovation and exploratory innovation on enterprise performance, and found that both exploratory innovation and exploratory innovation can improve enterprise performance, and different redundant resources play different regulating roles. Yunjie Qiu and Wei Wei (2016), based on the database of Chinese industrial enterprises from 1998 to 2009, found that R\&D behavior can effectively improve enterprise performance and significantly increase factor productivity and profit margin.

Second, the research on the impact of infrastructure on enterprises. Zhang Guangnan et al. (2010) found through research that infrastructure construction can reduce the production cost of manufacturing enterprises. Liu Juqiang and Zhao Yongliang (2010) concluded that transportation infrastructure has a significant impact on the development of manufacturing enterprises by overcoming natural barriers. Wang Yongjin (2017) found that the improvement of transportation infrastructure can promote the export of enterprises. Through the study on the opening of high-speed railway lines in China from 2007 to 2016, Ma Tao et al. (2020) concluded that the construction of high-speed railway significantly can improve enterprise performance and has a significant impact on the service industry.

Third, the research of Belt and Road and CR express. By analyzing the data on trade volume between China and Europe in the first half of 2018, Yu Min and Liu Yiming (2019) believed that the opening of CR express broadens the export market of China and accelerates the growth of the trade volume between China and Europe. Wang Xiongyuan and Bu Luofan (2019) studied the opening of $\mathrm{CR}$ express and concluded that it was conducive to strengthening the trade exchanges between China and cities along Belt and Road and improving the terms of trade of foreign trade enterprises. Fang Xingming et al. (2020) believed that transportation is an important factor affecting China's trade with other countries, and the opening of CR express has promoted China's trade with other countries along the routes. Hu Bing and Wang Xiaoping (2021), based on the microscopic data of 236 listed 
manufacturing companies from 2012 to 2018, found that the BRI has an improvement in enterprise performance.

\subsection{Research Hypothesis}

First, the opening of CR express has improved the terms of trade of enterprises and significantly reduced the trade costs of enterprises, including transportation costs and product costs (Anderson \& Van Wincoop, 2004). The concrete performance is as follows: First, the most important role of transportation infrastructure improvement is to reduce transportation costs, thus reducing the cost of enterprises and improving enterprise performance. Undeniably, sea transportation costs the lowest, but the speed is slow, and it is easy to be affected by weather, environment and so on, which reduces the safety and reliability of transportation, while air transport and road transport cost is higher. CR express reasonable construction of transportation hub-and-spoke network organization mode, can be radiated to the hub nodes of the range of hundreds of kilometers. In addition, the standardized container or vehicle transportation "five fixed freight trains" (fixed-point, fixed-line, fixed-train, fixed-time, and fixed-price) has the advantages of fast speed and high safety. Moreover, the largescale operation of CR express can reduce the inventory cost of enterprises, improve the capital turnover rate, and realize scale economy (Pei Changhong and Liu Bin, 2019). Second, after the opening of CR express, enterprises can sell their superior products to the countries along the Belt and Road, expand the sales channels, and share the product cost evenly to help reduce the product cost, achieve scale economy and improve enterprise performance. Third, the Chinese government has given more subsidies to CR express, which has further reduced the cost of enterprises. On the other hand, the government's orientation also makes it easier for enterprises to raise money from outside. It can be seen that CR express has advantages that other modes of transport do not have. It reduces trade costs, promotes enterprises to bring their products to a wider market, and promotes enterprise performance.

Secondly, the opening of CR express promotes industrial agglomeration and produces the effect of scale economy, thus promoting the development of enterprises and improving their performance. The opening of CR express has strengthened the economic ties among enterprises in the region, promoted industrial concentration, and created more favorable external conditions for the development of enterprises. Industrial agglomeration can not only share information, infrastructure and other resources, but also promote the division of labor and cooperation among enterprises, which is positively correlated with the benign competition and cooperation between enterprises (Wang Lili et al., 2009). In addition, industrial agglomeration will also promote the flow of talents and the exchange of management experience, which is conducive to the existing enterprises to use new technology and knowledge for industrial upgrading. At the same time, industrial agglomeration will also attract foreign investors. On the one hand, it will bring advanced technology and management experience. On the other hand, it brings a lot of financing to promote the development of enterprises. Therefore, CR express has brought new opportunities for the development of enterprises.

In conclusion, this paper proposes a research hypothesis: infrastructure connectivity promotes enterprise performance.

\section{Model, Data and Variable Description}

\subsection{Model Specification}

The Quasi-natural experiment is like completely randomized experiment in which individuals accept changes in the environment they face. Since the opening of CR express on March 19, 2011, the number of trains has increased annually, and the scope of cities and countries involved has continued to expand. However, there are still some cities that have not opened CR express. Based on such a structure, we can regard the CR express opening as a Quasi-natural experiment. In order to test whether the opening of CR express affects enterprise performance, this paper sets up a Differences-in-Differences model (DID): 
Volume 15 (2021)

$$
\begin{gathered}
\text { ROA }_{i, t}=\alpha_{0}+\alpha_{1} \text { AFTER } \times \text { RAD DIST } T_{i, t}+\alpha_{k} \text { LControls }_{i, t}^{k}+ \\
\sum \text { Firm FE }+\sum \text { Year FE }+\varepsilon_{i, t}
\end{gathered}
$$

In the above formula, $i$ represents the enterprise and $t$ represents the year. The explained variable $R O A$ is enterprise performance; The explanatory variable AFTER represents whether the CR express is open or not, $R A D$ DIST represents the distance between the enterprise and the nearest platform (abbreviated as DIST); Controls stand for a series of control variables; Firm FE denotes Firm fixed effect; Year FE represents annual fixed effect; $\varepsilon$ is a random disturbance term. $\alpha_{1}$ is the coefficient we focus on, which represents the average processing effect of the opening of CR express on enterprise performance. If significant is positive, it indicates that infrastructure connectivity promotes enterprise performance.

\subsection{Sample Selection and Data Sources}

Taking 8770 A-share manufacturing listed companies from 2009 to 2015 as the initial samples, and do the following treatments: (1) Eliminate ST, *ST and IPO company samples; (2) Eliminate the samples whose asset-liability ratio is abnormal, that is, the asset-liability ratio is not between 0 and 1 ; (3) Because this paper needs to match the micro data of enterprises with the city data of CR express, remove the samples of companies where the place of registration changes. Finally, 5,514 firm-year samples were obtained. The micro data of enterprises is from CSSAR database, the longitude and latitude of listed companies and stations are from AutoNavi Map WebAPI, and the information of the opening of CR express is from the website of China Railway Container Company, local official media and the website of local railway administration.

\subsection{Variable Description}

Explained variable: enterprise performance, measured by return on total assets $(R O A)$. Namely net profit after tax/total assets, used to measure how much net profit each unit of assets to create, reflecting the profitability of the enterprise.

Table 1. Descriptive statistics of variables

\begin{tabular}{|c|c|c|c|c|c|c|}
\hline variable & $\mathrm{N}$ & mean & $\mathrm{sd}$ & $\min$ & $\mathrm{p} 50$ & $\max$ \\
\hline$R O A$ & 5514 & 0.0564 & 0.0478 & -0.1238 & 0.0494 & 0.2188 \\
\hline$A F T E R$ & 5514 & 0.4206 & 0.4937 & 0 & 0 & 1 \\
\hline$R A D 100$ & 5514 & 0.4044 & 0.4908 & 0 & 0 & 1 \\
\hline$R A D 150$ & 5514 & 0.4840 & 0.4998 & 0 & 0 & 1 \\
\hline$R A D 200$ & 5514 & 0.5426 & 0.4982 & 0 & 1 & 1 \\
\hline$R A D 250$ & 5514 & 0.5742 & 0.4945 & 0 & 1 & 1 \\
\hline$R A D 300$ & 5514 & 0.6208 & 0.4852 & 0 & 1 & 1 \\
\hline$R A D 350$ & 5514 & 0.6634 & 0.4726 & 0 & 1 & 1 \\
\hline$R A D 400$ & 5514 & 0.7238 & 0.4472 & 0 & 1 & 1 \\
\hline$R A D 450$ & 5514 & 0.7492 & 0.4335 & 0 & 1 & 1 \\
\hline$R A D 500$ & 5514 & 0.7831 & 0.4122 & 0 & 1 & 1 \\
\hline$R A D 550$ & 5514 & 0.8012 & 0.3991 & 0 & 1 & 1 \\
\hline$R D$ & 5514 & 0.0315 & 0.0292 & 0 & 0.0293 & 0.1631 \\
\hline$C A S H$ & 5514 & 0.2151 & 0.1487 & 0.0187 & 0.1740 & 0.6766 \\
\hline$L E V$ & 5514 & 0.4075 & 0.2037 & 0.0467 & 0.4023 & 0.8731 \\
\hline$L I S T A G E$ & 5514 & 8.2196 & 5.9508 & 1 & 7 & 24 \\
\hline$P P E$ & 5514 & 0.2588 & 0.1473 & 0.0207 & 0.2297 & 0.6781 \\
\hline$S T A T E$ & 5514 & 0.3738 & 0.4838 & 0 & 0 & 1 \\
\hline$P E R S O N$ & 5514 & 0.1437 & 0.1284 & 0 & 0.1175 & 0.6503 \\
\hline
\end{tabular}


Core Explanatory Variable: AFTER $\times$ RAD DIST. AFTER means whether the railway hub station nearest to the listed company has been opened or not. If it has been opened, it is 1 , and if not, it is 0 . RAD DIST: Represent the distance from the platform, namely the shortest spherical distance (calculated by longitude and latitude) between the registered place of the listed company and the nearest starting station of CR express. The distances are in the order of $[0,100 \mathrm{~km}],[0,150 \mathrm{~km}],[0,200$ $\mathrm{km}] \ldots[0,500 \mathrm{~km}]$, RAD DIST $=1$; otherwise $=0$.

Controls include $\mathrm{R} \& \mathrm{D}$ intensity $(R D)$, that is , $\mathrm{R} \& \mathrm{D}$ expenditure/revenue of the current period; Cash holding level $(C A S H)$, that is, cash holdings/average total assets at the end of period; Company SIZE (SIZE) is the natural logarithm of the average total assets; Asset-liability ratio (LEV) is equal to total liabilities/total assets; Number of years of listed companies(LISTAGE); Proportion of fixed assets to total assets $(P P E)$; Property rights nature (STATE), that is, whether it is a state-owned enterprise (take 1 for state-owned enterprises, or take 0 for otherwise); Ratio of R\&D personnel to the number of employees (Person); In addition, the Firm fixed effect (Firm FE) is used to control the heterogeneity among listed companies, and the annual fixed effect (Year FE) is used to control other exogenous events that may exist during the sample period.

\subsection{Difference Test}

Table 2 reports the difference test results. The results of column (3) show that when the Hub-andspoke distance is 300, 350 and 400 kilometers, the enterprise performance of the experimental group is significantly lower than that of the control group; Under other Hub-and-spoke distances, the performance difference between the experimental group and the control group is not significant. The results in column (6) show that after the opening of CR express, there is a significant positive difference in enterprise performance between the experimental group and the control group. The differential results of column (7) show that when the Hub-and-spoke distance is less than $450 \mathrm{~km}$, the enterprise performance between the control group and the experimental group is significant at the $1 \%$ level. When the Hub-and-spoke distance is equal to $500 \mathrm{~km}$ and $550 \mathrm{~km}$, the enterprise performance between the control group and the experimental group is significant at the $5 \%$ level. In addition, with the increase of the Hub-and-spoke distance, the difference generally presents a decreasing trend.

Table 2. Difference test

\begin{tabular}{|c|c|c|c|c|c|c|c|}
\hline \multirow{2}{*}{$\begin{array}{c}\text { Hub-and- } \\
\text { spoke } \\
\text { distance }(\mathrm{km})\end{array}$} & \multicolumn{3}{|c|}{ Before opening } & \multicolumn{3}{|c|}{ After opening } & \multirow[b]{2}{*}{$\begin{array}{c}\text { DID } \\
(7)=(6)-(3)\end{array}$} \\
\hline & $\begin{array}{l}\text { Control } \\
\text { group }(1)\end{array}$ & $\begin{array}{l}\text { Experimental } \\
\text { group }(2)\end{array}$ & $\begin{array}{l}\text { Difference } \\
(3)=(2)-(1)\end{array}$ & $\begin{array}{l}\text { Control } \\
\text { group(4) }\end{array}$ & $\begin{array}{l}\text { Experimental } \\
\text { group }(5)\end{array}$ & $\begin{array}{l}\text { Difference } \\
(6)=(5)-(4)\end{array}$ & \\
\hline 100 & 0.058 & 0.057 & $-0.001(0.002)$ & 0.050 & 0.060 & $0.010 * * *(0.002)$ & $0.011 * * *(0.003)$ \\
\hline 150 & 0.059 & 0.057 & $-0.001(0.002)$ & 0.049 & 0.060 & $0.011 * * *(0.002)$ & $0.013 * * *(0.003)$ \\
\hline 200 & 0.059 & 0.057 & $-0.002(0.002)$ & 0.049 & 0.059 & $0.010 * * *(0.002)$ & $0.012 * * *(0.003)$ \\
\hline 250 & 0.059 & 0.057 & $-0.002(0.002)$ & 0.049 & 0.059 & $0.009 * * *(0.002)$ & $0.011 * * *(0.003)$ \\
\hline 300 & 0.061 & 0.056 & $\stackrel{-}{-} 0.005^{* * *}(0.002)$ & 0 & 0.05 & $0.008 * * *(0.002)$ & $(0.003)$ \\
\hline 350 & 0.061 & 0.057 & $-0.004 * *(0.002)$ & 0.050 & 0.057 & $0.007 * * *(0.002)$ & $0.011 * * *(0.003)$ \\
\hline 400 & 0.061 & 0.057 & $-0.004 *(0.002)$ & 0.050 & 0.056 & $0.006^{* * *}(0.002)$ & $0.010 * * *(0.003)$ \\
\hline 450 & 0.060 & 0.057 & $-0.003(0.002)$ & 0.050 & 0.056 & $0.006^{* * *}(0.002)$ & $0.008 * * *(0.003)$ \\
\hline 500 & 0.059 & 0.058 & $-0.001(0.002)$ & 0.050 & 0.056 & $0.005 * *(0.002)$ & $0.006^{* *}(0.003)$ \\
\hline 550 & 0.059 & 0.057 & $-0.002(0.002)$ & 0.051 & 0.055 & $0.005^{* *}(0.002)$ & $0.007 * *(0.003)$ \\
\hline
\end{tabular}

\section{Empirical Results}

\subsection{Results of Baseline Regression}

Table 3 lists the regression results of the opening of CR express and enterprise performance. After considering the influence of other factors, when the radiation distance is less than or equal to $450 \mathrm{~km}$, the regression coefficient of AFTER $\times$ RAD DIST is significantly positive at the $1 \%$ level, which is basically consistent with the results of single-variable test, indicating that the opening of CR express has a significant promoting effect on enterprise performance, that is, infrastructure connectivity 
promotes enterprise performance. In addition, with the increase of the Hub-and-spoke distance, the difference generally presents a decreasing trend.

Table 3. The regression results of the benchmark model

\begin{tabular}{|c|c|c|c|c|c|c|c|c|}
\hline & $(1)$ & $(2)$ & $(3)$ & $(4)$ & $(5)$ & $(6)$ & $(7)$ & $(8)$ \\
\hline$Y: R O A$ & $\begin{array}{c}\text { DIST } \\
<100\end{array}$ & $\begin{array}{c}\text { DIST } \\
<150\end{array}$ & $\begin{array}{c}\text { DIST } \\
<200\end{array}$ & $\begin{array}{c}\text { DIST } \\
<250\end{array}$ & $\begin{array}{c}\text { DIST } \\
<300\end{array}$ & $\begin{array}{c}\text { DIST } \\
<350\end{array}$ & $\begin{array}{c}\text { DIST } \\
<400\end{array}$ & $\begin{array}{c}\text { DIST } \\
<450\end{array}$ \\
\hline $\begin{array}{c}\text { AFTER } \\
\times \text { RAD DIST }\end{array}$ & $0.0086^{* * *}$ & $0.0087^{* * *}$ & $0.0082^{* * *}$ & $0.0078^{* * *}$ & $0.0077^{* * *}$ & $0.0070^{* * *}$ & $0.0065^{* * *}$ & $0.0053^{* * *}$ \\
\cline { 2 - 9 } Controls & $(0.0019)$ & $(0.0018)$ & $(0.0018)$ & $(0.0017)$ & $(0.0017)$ & $(0.0017)$ & $(0.0017)$ & $(0.0018)$ \\
\hline Firm\&Year FE & $\mathrm{Y}$ & $\mathrm{Y}$ & $\mathrm{Y}$ & $\mathrm{Y}$ & $\mathrm{Y}$ & $\mathrm{Y}$ & $\mathrm{Y}$ & $\mathrm{Y}$ \\
\hline$N$ & 5514 & 5514 & $\mathrm{Y}$ & $\mathrm{Y}$ & $\mathrm{Y}$ & $\mathrm{Y}$ & $\mathrm{Y}$ & $\mathrm{Y}$ \\
\hline Adj $R^{2}$ & 0.1050 & 0.1057 & 0.1053 & 0.1047 & 0.1047 & 0.1037 & 0.1030 & 0.1017 \\
\hline
\end{tabular}

\subsection{Robustness Examination}

\subsubsection{Parallel Trend Test}

One of the prerequisites for the effectiveness of DID is the hypothesis of parallel trend, that is, the treatment group and the control group must have the same development trend before the implementation of the policy of the opening of CR express. In other words, the policy effect obtained by the two differences is the real policy effect, rather than caused by the difference between the treatment group and the control group.

In order to test the parallel trend, this paper multiplies the virtual of the experimental group with the virtual variables of the year before, the year after, and the two years after the implementation of the policy, respectively, to identify the specific effects of the parallel trend and the policy in different years. This study found that the change trend of the experimental group and the control is the same in the year and the previous year, but there is no significant difference. Then, the estimated results of the two years after the opening of CR express are significant, which indicates that the opening of CR express has a positive impact on the increase of enterprise performance, and it is getting stronger and stronger as time goes on. Therefore, the sample can be considered to pass the parallel trend test.

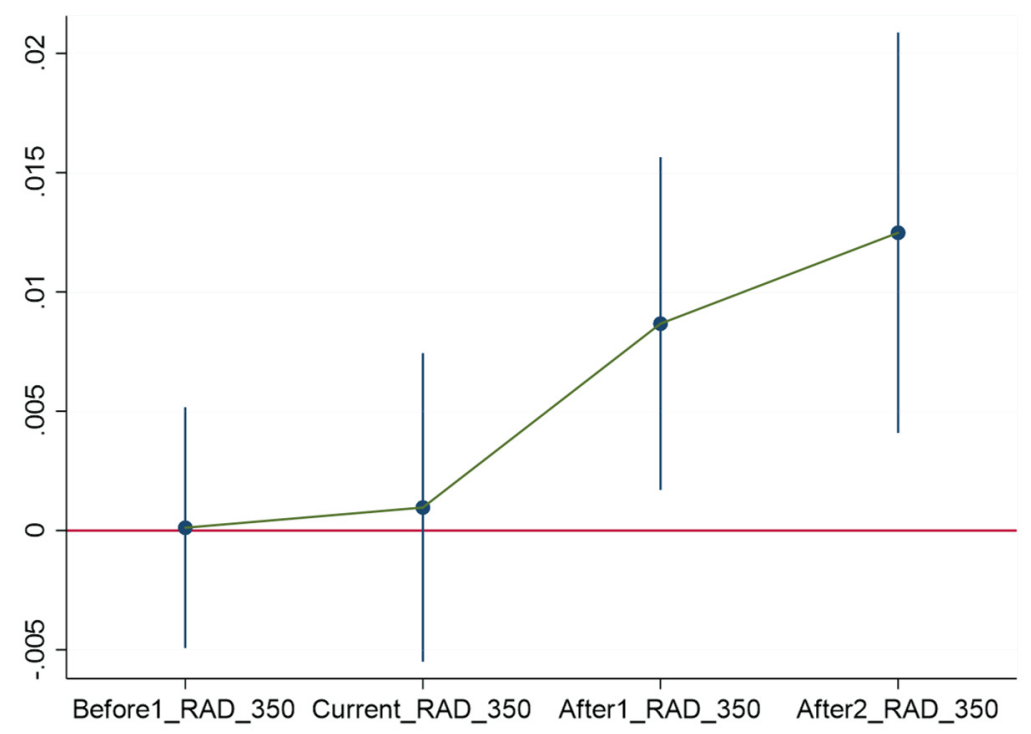

Figure 1. Parallel trend test

Note: Figure 1 shows the results of the parallel trend test for the $350 \mathrm{~km} \mathrm{Hub}$-and-spoke distance. The solid vertical line represents the $95 \%$ confidence interval for the estimated coefficient. The results of other Hub-and-spoke distances are also basically passed, which will not be repeated here. 


\subsubsection{Check the Change Trend of Geographical Distance}

In order to verify the geographical distribution of the impact of CR express on enterprise performance, to show its impact on enterprise performance is decreasing gradually. In this paper, the change trend of geographic distance is tested, a set of $R A N G E$ variables, respectively express whether the distance between the enterprise and the CR express hub station distance DIST is located in the [0,100 kilometers], [100 km, $200 \mathrm{~km}],[200 \mathrm{~km}, 300 \mathrm{~km}],[300 \mathrm{~km}, 400 \mathrm{~km}],[400 \mathrm{~km}, 500 \mathrm{~km}]$, and put the AFTER $\times$ RANGE DIST into the original model for regression analysis. As shown in Table 4 show that the coefficient of AFTER $\times$ RANGE DIST is positive within the $R A N G E[0,300 \mathrm{~km}]$, and then is significantly negative, indicating that the opening of CR express may have a negative siphon effect on enterprises with a long distance (Qin, 2016). Therefore, it is concluded that the impact of CR express on enterprise performance gradually decreases along the geographical distance distribution, and CR express should conduct further research on station planning and other issues so as to reduce the negative impact caused by the too long distance of infrastructure.

Table 4. Dynamic test of geographical distance

\begin{tabular}{|c|c|}
\hline Variables & $(1)$ \\
\hline AFTER $\times$ RANGE 100 & $0.0086^{* * *}(0.0022)$ \\
\hline AFTER $\times$ RANGE 200 & $0.0044^{*}(0.0025)$ \\
\hline AFTER $\times$ RANGE 300 & $0.0015(0.0038)$ \\
\hline AFTER $\times$ RANGE 400 & $-0.0010(0.0030)$ \\
\hline AFTER $\times$ RANGE 500 & $-0.0074(0.0048)$ \\
\hline Controls & $\mathrm{Y}$ \\
\hline Firm\&Year FE & 5465 \\
\hline Observations & 0.1069 \\
\hline Adj R-squared & $\mathrm{Y}$ \\
\hline
\end{tabular}

\subsubsection{Sample Selection Bias}

Since enterprises tend to register in cities with higher development level, and these cities are more likely to be within the scope of the axis of CR express, which threatens the randomness of the opening of CR express, there may be a sample selection bias problem. Therefore, in this paper, the propensity score matching method (PSM) is used to process the samples, and differential estimation (DID) is performed after sample matching.

Select the level of economic development (per capita GDP), the rate of fiscal autonomy (finance income/expenditure), industrial structure(secondary and tertiary industry output value proportion), population density, development level (such as import and export trade volume/GDP) as covariates (Long Yu, 2017). The matching methods of 1:1 nearest neighbor matching, nuclear matching radius matching are used to match the prefecture-level cities inside and outside the spoke network. The results of the balance test show that, (Due to space, the results of the balance test are not be reported.) except for the nearest neighbor matching, other matching methods basically satisfy the common support domain hypothesis, so we focus on the results of nuclear matching and radius matching. The matched samples are estimated by DID, and the regression results are shown in Table 5 . When the Hub-and-spoke distance is equal to $250 \mathrm{~km}$ and $300 \mathrm{~km}$, the regression coefficient of $A F T E R \times R A D$ 
$D I S T$ is significantly positive, and the estimated coefficient is also very close to the baseline regression. The results of other axial amplitude distances are also basically significantly positive.

Table 5. Analysis based on propensity score matching samples

\begin{tabular}{|c|c|c|c|c|c|c|}
\hline & \multicolumn{2}{|c|}{ Nearest neighbor matching } & \multicolumn{2}{c|}{ Nuclear matching } & \multicolumn{2}{c|}{ Radius matching } \\
\hline & $(1)$ & $(2)$ & $(3)$ & $(4)$ & $(3)$ & $(4)$ \\
\hline$Y: R O A$ & DIST & DIST & DIST & DIST & DIST & DIST \\
& $<250$ & $<300$ & $<250$ & $<300$ & $<250$ & $<300$ \\
\hline AFTER & 0.0039 & $0.0057^{* * *}$ & $0.0072^{* * *}$ & $0.0080^{* * *}$ & $0.0077^{* * *}$ & $0.0080^{* * *}$ \\
$\times$ RAD DIST & $(0.0025)$ & $(0.0021)$ & $(0.0018)$ & $(0.0018)$ & $(0.0018)$ & $(0.0017)$ \\
\hline Controls & Y & Y & Y & Y & Y & Y \\
\hline Firm\&Year FE & Y & Y & Y & Y & Y & Y \\
\hline$N$ & 2418 & 2579 & 4694 & 5382 & 5301 & 5419 \\
\hline Adj $R^{2}$ & 0.0840 & 0.0734 & 0.1051 & 0.1052 & 0.1071 & 0.1052 \\
\hline
\end{tabular}

\section{Conclusions and Suggestions}

The world economy is undergoing complex and profound changes. The impact of the international financial crisis is becoming more apparent. Under the background of world multi-polarization and diversified economy and culture, the implementation of the BRI has promoted the establishment of a free trade system. The CR express has become the key to the trade between China and Europe. It has effectively alleviated the trade barriers caused by geographical problems and made the export of enterprises more convenient and efficient. This paper takes the opening of CR express as a Quasinatural experiment, and tests whether it affects corporate performance through the establishment of a differential model (DID). The study found that the opening of CR express promoted enterprise performance by promoting infrastructure connectivity, and the promoting effect gradually weakened with the increase of Hub-and-spoke distance. After a series of robustness tests, such as parallel trend test, geographical distance change trend test, sample selection bias test, etc., the promotion effect of the opening of CR express on enterprise performance is still stable.

This paper draws the following policy implications: First, the number of CR express and the number of cities to be opened should be increased. CR express has become the backbone of international land logistics transportation. The empirical results show that the establishment of CR express can promote enterprise performance, promote enterprises' export to countries along the Belt and Road, and expand the trade market of enterprises. Therefore, we can appropriately increase the number of CR express and the number of cities opened to help more enterprises to expand sales channels through CR express, so as to promote the trade between China and other countries. Secondly, the Chinese government still needs to increase the investment in infrastructure construction to further develop inter-city connectivity. The improvement of domestic infrastructure connectivity will help to further expand the positive effect of the opening of CR express and create more convenient conditions for the export trade of Chinese enterprises. At the same time, the deepening of foreign trade can also promote industrial agglomeration in cities and promote the development of enterprises. Finally, the government should establish a more perfect logistics service system of CR express. For a long time, the international trade pattern is dominated by sea transportation, which leads to a growing economic gap between the west and the east of China, and the west is limited by geographical conditions. The opening of CR express has improved the convenience of foreign trade in the western region. Therefore, the government should further optimize the logistics service system of CR express.

There are still some shortcomings in this study, such as the failure to distinguish the connection strength of different China-Europe freight train stations and the failure to study the further connection between enterprises under the opening of CR express. These problems will be the key points of the next study. 


\section{References}

[1] Fang Fuqian, Tian Ge, Xiao Han.The impact of infrastructure on China's economic growth and its mechanism: Based on the expansion of Barro growth model [J]. Economic Theory and Management, 2020 (12): 13-27.

[2] Wang Yongjin, Huang Qing. Transportation infrastructure quality, time sensitivity and export performance [J]. Finance and Economics Research,2017,43(10):97-108.

[3] Shi Zhenkai, Shao Jun, Pu Zhengning.Transportation infrastructure improvement and productivity growth: Evidence from the great railway speed increase [J]. World Economy,2018,41(06):127-151.

[4] Zhang Tianhua, Chen Li, Dong Zhiqiang.Freeway construction, enterprise evolution and regional economic efficiency [J]. China Industrial Economics,2018(01):79-99.

[5] Li Han, Tang Limiao. Transportation infrastructure investment, spatial spillover effect and enterprise inventory [J]. Management World,2015(04):126-136.

[6] Ma Tao, Chang Xiaoying, Huang Yin.An Empirical Study of High-speed Rail Network Access, Enterprise Performance Improvement and Innovation Promoting Based on Quasi-natural Experiment [J]. Economics and Management Research,2020,41(03):106-116.

[7] Chen Deping, Zeng Zhihai. The relationship between capital structure and firm performance: A case study of listed companies in GEM [J]. Accounting Research,2012(08):66-71+97.

[8] LI Jian li. The relationship between exploratory innovation, development innovation and firm performance: An empirical analysis based on the moderating effect of slack resources [J].Studies in Science of Science, 2009,27(09):1418-1427.

[9] Qiu Yunjie, Wei Wei. The impact of R\&D investment on firm performance: Based on propensity score matching method [J]. Contemporary Finance and Economics,2016(03):96-106.

[10] Zhang Guangnan, Zhu Hongjia, Chen Guanghan. The impact of infrastructure on production cost and input factors of Chinese manufacturing enterprises: Based on panel data analysis of 27 manufacturing enterprises in China from 1998 to 2005 [J]. Statistical Research,2010,27(06):46-57.

[11] LIU Juqiang, ZHAO Yongliang. Transportation infrastructure, market access and manufacturing location: Empirical data from China [J].Nankai Economic Research Journal,2010(04):123-138.

[12] Ma Tao, Chang Xiaoying, Huang Yin.An Empirical Study of High-speed Rail Network Access, Enterprise Performance Improvement and Innovation Promoting Based on Quasi-natural Experiment [J]. Economics and Management Research,2020,41(03):106-116.

[13] Yu Min, Liu Yiming. Analysis on the attraction and prospect of Sino-Europe freight train and Sino-Europe trade based on trade gravity model [J]. Research on Economic Problems,2019(10):125-133.

[14] Wang Xiongyuan, Bu Luofan. International Export Trade and Enterprise Innovation: A Quasi-natural Experimental Study Based on the Opening of "China-Europe Railway" [J]. China Industrial Economics, 2019 (10): 80-98.

[15] Fang Xingming, Lu Yuxiu, Wei Jing. The impact of the opening of China-Europe freight train on the trade openness of Chinese cities: Based on the perspective of "One Belt and One Road" construction [J]. International Economic and Trade Exploration,2020,36(02):39-55.

[16] Hu Bing, Wang Xiaoping. "One Belt and One Road" initiative and Chinese firm performance -- based on micro data analysis of manufacturing listed companies [J]. Contemporary Economic Research Journal, 2021 (02):64-74.

[17] James E Anderson, Eric Van Wincoop. Trade Costs [J]. Journal of Economic Literature,2004,42(3).

[18] Pei Changhong, Liu Bin.Social Sciences in China,2020(02):46-69+205. (In Chinese).

[19] Wang Lili, Lu Wei, Zhou Ying, Guo Bing.Industrial Engineering and Management,2009,14(06):96-102. (In Chinese).

[20] Yu Qin. 'No county left behind? The Contribution of Upgrades to High-Speed Rail in China' [J]. Journal of Economic Geography,2017, 17(3).

[21] Long Yu, Zhao Hailong, Zhang Xinde, Li Yao.Venture capital under space-time compression: The opening of high-speed railway and regional change of venture capital [J]. Economic Research Journal, 2017, 52(04):195-208. 